\title{
The Effects of Hypoxia on (Methionine) Enkephalin Peptide and Catecholamine Release in Fetal Sheep
}

\author{
ALMA M. MARTINEZ, JAMES F. PADBURY, ELIZABETH E. BURNELL, SIANG L. THIO, AND \\ JAMES HUMME \\ Harbor-UCLA Medical Center, UCLA School of Medicine, Torrance, California 90509
}

\begin{abstract}
The effect of hypoxia on plasma met-enkephalin and catecholamine levels was studied in chronically catheterized fetal sheep. Maternal and fetal hypoxia was maintained for $20 \mathrm{~min}$. We found hypoxia significantly increased the plasma levels of large mol wt met-enkephalin containing peptides from $1755 \pm 229 \mathrm{pg} / \mathrm{mL}$ during baseline to $4408 \pm 1426 \mathrm{pg} / \mathrm{mL}$ by 15 minutes of hypoxia. The levels of the met-enkephalin pentapeptide were unchanged during hypoxia from a baseline value of $168 \pm 56 \mathrm{pg} / \mathrm{mL}$. Norepinephrine and epinephrine levels increased 5- and 10-fold, respectively, by $15 \mathrm{~min}$ of hypoxia. These observations suggest cosecretion of the large mol wt met-enkephalin peptides with catecholamines during stress in developing animals. (Pediatr Res 27: 52-55, 1990)
\end{abstract}

\section{Abbreviations}

MET-ENK, methionine-enkephalin

LEU-ENK, leucine enkephalin

MET-ENKi, methionine enkephalin immunoreactivity

The opiate peptides (endorphins and enkephalins) have been shown to have significant physiologic effects on autonomic responses of fetal and neonatal cardiovascular (1) and respiratory systems $(2,3)$ in humans and animals. The enkephalin peptides are postulated to influence these systems centrally (4), as well as peripherally, by inhibitory effects on neurotransmission in sympathetic ganglia $(5,6)$ and on adrenal medullary catecholamine release (7).

The enkephalins have been localized in brainstem nuclei involved in autonomic regulation, sympathetic neurons and sympathetic ganglia, intestinal neurons and ganglia, and in chromaffin granules of the adrenal medulla (8-10). In the adrenal chromaffin cells, they are found costored with catecholamines as pentapeptides, MET-ENK, LEU-ENK, and as larger mol wt forms, including carboxy-extended forms of MET-ENK and the enkephalin prohormone $(9,10)$. In vitro and in situ studies show all forms of the enkephalins are secreted with catecholamines in response to a variety of stimuli $(9,11)$.

There have been few studies on the secretion of enkephalin peptides in intact, unanesthetized developing animals. Important maturational effects on fetal and neonatal catecholamine secretion have been described $(12,13)$. We therefore designed exper-

Received March 14, 1989; accepted September 6, 1989

Reprints Alma M. Martinez, M.D., Harbor-UCLA Medical Center, UCLA School of Medicine, 1000 West Carson Street, Research Building no. 1, Torrance, CA 90509.

Supported in part by USPHS Grants HD-22003, HD-18014, and HD 07013. iments to measure the circulating plasma levels of the METENK peptides in fetal sheep in response to hypoxia.

\section{MATERIALS AND METHODS}

Surgical procedures. Date-mated Western mixed-breed ewes $(n=5)$ with single fetuses were catheterized at $116-118 \mathrm{~d}$ of gestation (term $=150 \mathrm{~d}$ ). The ewes were sedated preoperatively with ketamine $(800 \mathrm{mg})$ and atropine $(1.2 \mathrm{mg})$ and received a constant infusion of ketamine $(8-10 \mathrm{mg} / \mathrm{min})$ during the operation. The fetal hindleg was exteriorized through a uterine incision. After local anesthesia of the fetal leg (1\% lidocaine), polyvinyl catheters were placed in an artery and vein and advanced to the level of the descending aorta and the inferior vena cava, respectively. An additional catheter was placed in the uterus to allow measurement of amniotic fluid pressure. The uterine incision was closed with all catheters tunneled subcutaneously in the maternal flank and stored in a cloth pouch sewn to the skin of the ewe. The ewe also had catheters placed into the femoral vein and artery that were tunneled subcutaneously and stored with the fetal catheters. Oxacillin and gentamycin were given intravenously for $3 \mathrm{~d}$ postoperatively to both mother and fetus. Animals were allowed to recover a minimum of $5 \mathrm{~d}$ before any studies were performed.

Experimental protocol. Fetal studies were carried out between 122 and $125 \mathrm{~d}$ of gestation. On the day of study, the fetal arterial catheter and the intrauterine pressure catheters were connected to Statham P23dB pressure transducers that were attached to a Sensormedics R61 I rectilinear polygraph (Sensormedics Corporation, Anaheim, CA). Fetal arterial blood gases and hematocrit were obtained. Arterial blood pressure, heart rate, and amniotic fluid pressure were monitored and allowed to stabilize for 30 min before experimental manipulation.

During the resting baseline period, duplicate arterial blood samples were obtained for measurement of plasma MET-ENK, epinephrine, norepinephrine, and arterial blood gas analysis. Resting baseline measurements of arterial blood pressure and fetal heart rate were also recorded. Fetal arterial pressure was corrected by subtraction of the measured amniotic fluid pressure.

After the baseline measurements, hypoxia was produced by placing a clear plastic bag over the ewe's head and delivering a gas mixture of nitrogen and oxygen to maintain an $\mathrm{FiO}_{2}$ in the range of $10-12 \%$. The fetal $\mathrm{PaO}_{2}$ was monitored and the oxygen delivery was adjusted to maintain the fetal $\mathrm{PaO}_{2}$ between 12 and $14 \mathrm{~mm} \mathrm{Hg}$.

Fetal arterial blood was obtained after 5, 10, 15, and $20 \mathrm{~min}$ of hypoxia for measurement of plasma MET-ENK, epinephrine, norepinephrine, and arterial blood gas analysis. The fetal heart rate, systolic blood pressure, and mean blood pressure were recorded at these same time points. Approximately $4 \mathrm{~mL}$ of fetal blood was removed at each sampling period and was replaced 
with heparinized maternal blood obtained before experimental manipulation.

The arterial blood for MET-ENK analysis was placed into chilled test tubes containing sodium citrate $(12 \mathrm{mM}$ final concentration). The blood for catecholamine analysis was placed into chilled tubes containing EGTA [ $4 \mathrm{mM}$, (ethylene glycol bis ( $\beta$-amino-ethyl ether) $N, N, N^{\prime} N^{\prime}$-tetra acetic acid)] and reduced glutathione $(3 \mathrm{mM})$. The samples were centrifuged immediately and the plasma was separated and stored at $-70^{\circ} \mathrm{C}$ until analysis was performed.

Analytical techniques. Plasma for measurement of MET-ENK was first extracted through polystyrene columns (14) and then measured by RIA using commercial antiserum (Immunoclear, Stillwater, MN). This antiserum cross-reacts $2.8 \%$ with leuenkephalin. Thus all measurements represent MET-ENKi. Plasma for measurement of the high mol wt enkephalin peptides or total MET-ENKi first underwent sequential proteolytic digestion with trypsin and carboxypeptidase B as previously described (11). The plasma was then extracted and measured with RIA as described above. The assay was sensitive to $2.3 \pm 0.3 \mathrm{pg}$. The inter- and intrassay variability were 13 and $9 \%$, respectively. Recovery of MET-ENK using this technique was determined to be more than $90 \%$ after 1000,500 , or $200 \mathrm{pg} / \mathrm{mL}$ additions to unextracted plasma. All enkephalin samples from each study period were extracted, digested, and measured in the same assay. Catecholamines were measured by a radioenzymatic assay sensitive to $1-2 \mathrm{pg}$ of norepinephrine and epinephrine as previously described (15).

To characterize the plasma MET-ENK immunoreactivity, plasma was subjected to gel filtration. Unextracted pooled fetal plasma was applied to a Sephadex G-75 column $(0.9 \times 57 \mathrm{~cm})$ equilibrated with $1 \mathrm{~N}$ acetic acid and eluted at $0.5 \mathrm{~mL} / \mathrm{min}$. Fractions of $1 \mathrm{~mL}$ were collected and dried in a vacuum evaporator and then assayed for MET-ENK. A second aliquot of the fetal plasma was separated on the same Sephadex column and fractions were collected identically. After vacuum evaporation, samples were subjected to trypsin and carboxypeptidase B digestion before extraction and assay for MET-ENK by RIA. This second aliquot represents total MET-ENKi (high mol wt enkephalin peptides). This procedure was repeated in triplicate using pooled fetal plasma before and after hypoxia.

Data analysis. Data are presented as mean and SEM. The catecholamine data was log transformed prior to statistical analysis and the values are presented as the geometric mean \pm SEM. Analysis of variance was used for statistical comparisons during hypoxia and Dunnett's test was used to compare data during hypoxia to the baseline data. A $p$ value $<0.05$ was considered statistically significant.

\section{RESULTS}

The paired samples for catecholamines, enkephalin peptides, and the biophysical data before hypoxia were not statistically different and were combined and are presented as baseline values. The data in Table 1 show the biophysical measurements made during the baseline period and during hypoxia in the fetal sheep. The fetal $\mathrm{PaO}_{2}$ decreased to a mean value of $14 \pm 0.3 \mathrm{~mm} \mathrm{Hg}$ at $20 \mathrm{~min}$ from a baseline value of $24 \pm 1 \mathrm{~mm} \mathrm{Hg}$. There was a small increase in systolic blood pressure and a significant decrease in fetal heart rate during hypoxia. Systemic $\mathrm{pH}$ was not statistically different during the short duration of hypoxia. Baseline control values for the MET-ENK peptides, norepinephrine, and epinephrine are shown in Figures 1 and 2. The baseline values for the circulating MET-ENK plasma levels show the higher mol wt forms of enkephalins (total MET-ENKi) predominant with mean baseline levels of 1755 versus $168 \mathrm{pg} / \mathrm{mL}$ for MET-ENKi (the low mol wt peptides). The baseline values for norepinephrine and epinephrine levels were similar to data previously reported by our laboratory and others $(16,17)$ and were believed to represent healthy, nonstressed animals.
Norepinephrine and epinephrine were significantly elevated during hypoxia to maximum values of $2582 \pm 366$ and $676 \pm$ $731 \mathrm{pg} / \mathrm{mL}$, respectively, by $15 \mathrm{~min}$ of hypoxia (Fig. 1). As seen in Figure 2, circulating plasma levels of total MET-ENKi were significantly increased during hypoxia with a mean of $4408 \pm$ $1426 \mathrm{pg} / \mathrm{mL}$ during the $15-\mathrm{min}$ sampling period versus the baseline value of $1755 \mathrm{pg} / \mathrm{mL}$. The pentapeptide (MET-ENKi) levels were not statistically different during hypoxia from baseline values of $168 \mathrm{pg} / \mathrm{mL}$.

Control experiments for the effects of time and sampling procedure were carried out on two additional animals. A clear plastic bag was placed over the head of the ewe and she was allowed to breathe room air. Using the same sampling times and blood vol, we drew blood from the fetus for catecholamine and enkephalin peptide analysis and replaced it with an equal vol of heparinized maternal blood. Although these animals were at an older gestational age (132 and $137 \mathrm{~d}$ ), we found no significant changes in fetal plasma enkephalin peptides MET-ENKi or total MET-ENKi) from baseline values of $162 \pm 22$ and $2886 \pm 364$ $\mathrm{pg} / \mathrm{mL}$, respectively. Similarly, there were no statistically significant changes from baseline values for norepinephrine $(835 \pm$ $180 \mathrm{pg} / \mathrm{mL})$, epinephrine $(35 \pm 10 \mathrm{pg} / \mathrm{mL})$, systolic blood pressure $(61 \pm 3 \mathrm{~mm} \mathrm{Hg})$, heart rate $(169 \pm 10 \mathrm{bpm})$, or fetal arterial blood gas values.

The gel filtration results are shown in Figure 3. As can be seen, the plasma immunoreactivity designated MET-ENKi coeluted precisely with MET-ENK standard. Plasma first separated by gel filtration and then subjected to trypsin and carboxypeptidase B, yielded the profile designated total MET-ENKi. As can be seen, the total MET-ENKi elution profile extended over a broad range. Plasma protein substrates of a mol wt range from 17000 to 80000 yielded MET-ENKi when subjected to the digestion procedure. There was no difference in the mol wt profiles from pooled plasma obtained before or after initiation of hypoxia.

\section{DISCUSSION}

In this study, we investigated the effects of hypoxia on circulating levels of both MET-ENK and catecholamines in fetal sheep. We noted a significant increase in the large mol wt forms of enkephalins when fetal sheep were exposed to significant but brief periods of hypoxia. We noted also a significant increase in the circulating levels of catecholamines and a physiologic response of the fetus to hypoxia with a significant degree of bradycardia. In contrast to the large mol wt enkephalin peptide response to hypoxia, we noted no change in the pentapeptide MET-ENKi.

There is limited in vivo data on the circulating levels of METENK in animals exposed to physiologic stress. Increased levels of the circulating MET-ENK pentapeptides have been described in adult dogs and cats exposed to hypovolemia $(18,19)$. In dogs exposed to hypoglycemia, increased levels of the large mol wt peptides have been described with no change noted in the pentapeptide levels (20).

The enkephalin peptides are found costored as pentapeptides and as larger mol wt forms with catecholamines in adrenal medullary chromaffin cells $(9,10)$. Review of enkephalin peptide content in adrenal medullary cells suggest as little as $10 \%$ of the total enkephalin equivalents are stored as the pentapeptides (10). All forms of these peptides are coreleased with catecholamines from the adrenal gland during physiologic stimuli in situ (11, 21). Furthermore, studies suggest a differential release of the enkephalin peptides, with small amounts of low mol wt peptides being released with low degrees of depolarization and greater amounts of the larger mol wt forms being released with higher degrees of depolarization (11).

The use of proteolytic digestion of plasma has been previously reported to substantially increase the yield of MET-ENKi (11, 22). Investigators have shown that plasma treated with trypsin 
Table 1. Biophysical data for fetal sheep during the baseline period and during hypoxia (mean \pm SEM)

\begin{tabular}{|c|c|c|c|c|c|}
\hline & \multirow[b]{2}{*}{ Baseline } & \multicolumn{4}{|c|}{ Hypoxia } \\
\hline & & $5 \mathrm{Min}$ & $10 \mathrm{Min}$ & 15 Min & $20 \mathrm{Min}$ \\
\hline $\mathrm{PaO}_{2}$ & $24 \pm 1$ & $15 \pm 0.4^{*}$ & $14 \pm 0.3^{*}$ & $14 \pm 1^{*}$ & $14 \pm 0.3^{*}$ \\
\hline $\mathrm{pH}$ & $7.37 \pm 0.01$ & $7.38 \pm 0.02$ & $7.38 \pm 0.02$ & $7.36 \pm 0.02$ & $7.35 \pm 0.02$ \\
\hline Heart rate $(\mathrm{bpm})$ & $179 \pm 5$ & $121 \pm 9^{*}$ & $124 \pm 7^{*}$ & $129 \pm 6^{*}$ & $134 \pm 4^{*}$ \\
\hline Systolic blood pressure $(\mathrm{mm} \mathrm{Hg})$ & $61 \pm 3$ & $63 \pm 4$ & $65 \pm 6$ & $74 \pm 5$ & $69 \pm 6$ \\
\hline Mean blood pressure $(\mathrm{mm} \mathrm{Hg})$ & $47 \pm 3$ & $58 \pm 3$ & $50 \pm 5$ & $55 \pm 5$ & $49 \pm 4$ \\
\hline
\end{tabular}

* Denotes statistically different from baseline, $p<0.05$ (analysis of variance, with Dunnett's).

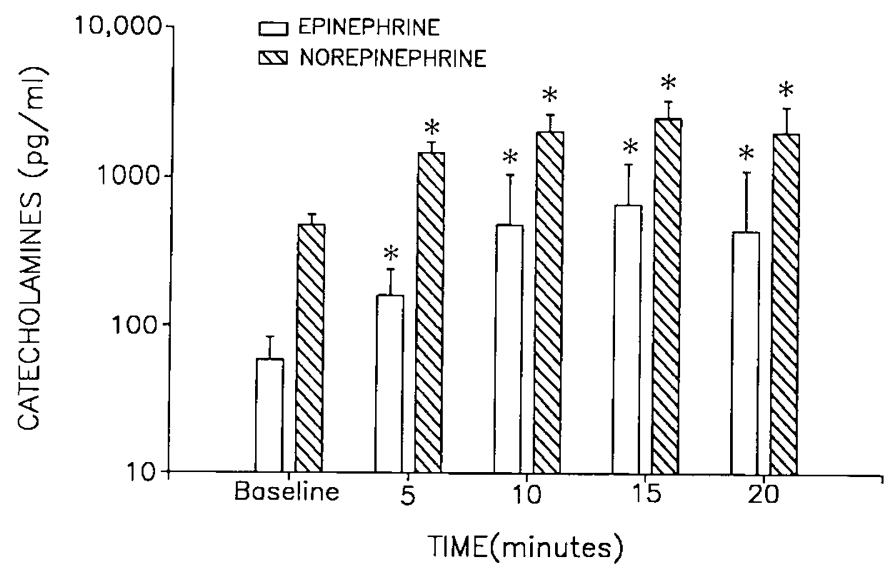

Fig. 1. Catecholamine levels during hypoxia. Values expressed as geometric mean \pm SEM. "Denotes statistical significance when compared to baseline. [Norepinephrine $\mathrm{F}(4,24)=11.56$, epinephrine $\mathrm{F}(4,24)=$ $3.63 p<0.05$, ANOVA with Dunnett's test.]

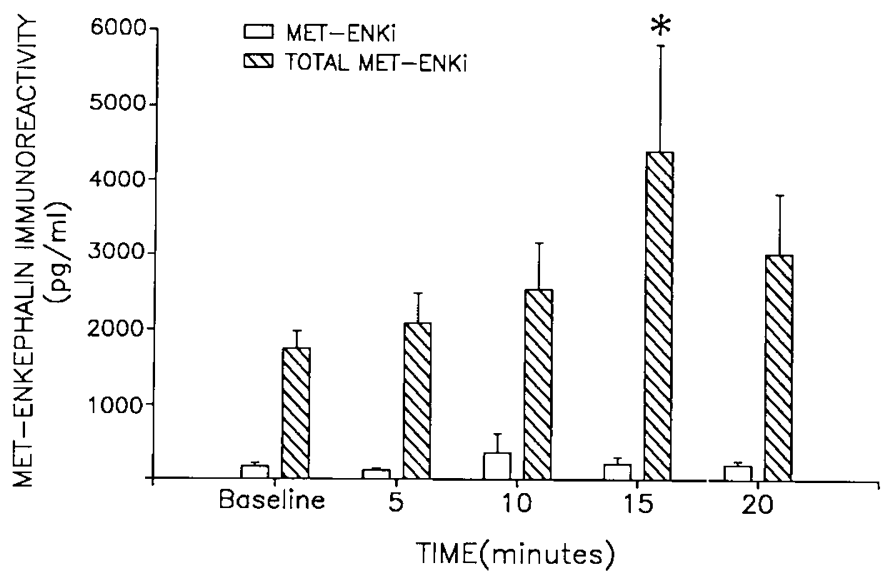

Fig. 2. MET-ENK immunoreactivity during hypoxia. Values expressed as mean \pm SEM. "Denotes statistical significance when compared to baseline. [Total MET-ENKi F $(4,24)=2.5, p<0.05$, ANOVA with Dunnett's test.]

and carboxypeptidase B yields MET-ENKi which coelutes with MET-ENK standard as well as carboxyl-extended forms of METENK using gel filtration and $\operatorname{HPLC}(11,21,22)$. Attempts to characterize the substrates yielding immunoreactive products have shown contrasting results. Although the products of the digestion procedures have been shown to be immunologically and chromatographically identical to MET-ENK, treatment of rat plasma with pepsin, a more nonphysiologic proteolysis, also yields measurable levels of MET-ENK (23). Generally, a relatively broad range of mol wt substrates from plasma have been shown to yield MET-ENKi after digestion with trypsin and carboxypeptidase $\mathrm{b}(11,21,22)$. This has been true in both developing and adult animals. Whether this represents digestion

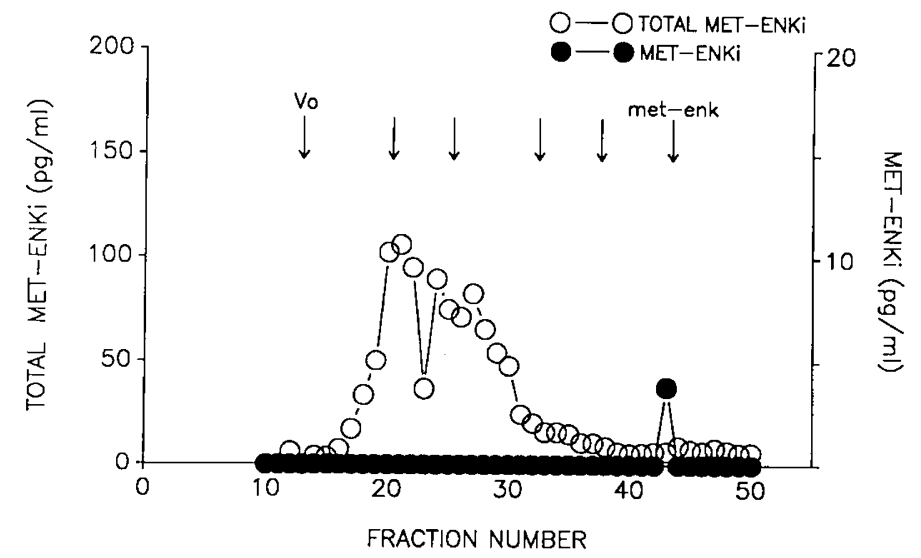

Fig. 3. Gel filtration of fetal sheep plasma. MET-ENKi represents undigested plasma measured by RIA. Total MET-ENKi represents metenkephalin immunoreactivity after sequential digestion with trypsin and carboxypeptidase B. Vo represents void volume determined with Dextran blue 2000. Other calibration markers used were ribonuclease A (mol wt $13700)$, chymotrypsinogen A $(25,000)$, ovalbumin $(43000)$, and albumin $(67000)$. Elution of standard MET-ENK peptide is indicated by arrow marked MET-ENK.

from multimeric forms of the proenkephalin proteins in circulation or nonspecific substrates deserves further careful study.

The physiologic role of opiate peptides has been the subject of many recent investigations. The opiate peptides and their receptors have been identified in CNS areas important for autonomic, cardiovascular, and respiratory control $(3,4)$, as well as in sympathetic ganglia (8) and the adrenal medulla $(9,10)$. The colocalization of these peptides and their receptors has suggested a role as modulators of the sympathoadrenal system. Previous studies have shown the opiate peptides inhibit norepinephrine release in sympathetic ganglia through presynaptic inhibition of cholinergic transmission probably through reduced acetylcholine release $(5,6)$. Opiate peptides have also been shown to inhibit adrenal catecholamine release in vitro in response to cholinergic stimulation (7). Data in adult animals suggest the opiate peptides are involved in the circulatory function of animals under physiologic stress and are responsible for some of the deleterious cardiovascular changes seen in animals with hemorrhagic (4), endotoxic (24-26), and spinal shock (4). Numerous in vivo studies using opiate peptide antagonists have shown increases in circulating catecholamines, as well as improvement in blood pressure and circulatory function in different animal models during shock $(25-29)$. Similar findings have been reported in human newborns (30). We have recently shown opiate receptor blockade with naloxone significantly augments epinephrine levels in fetal sheep exposed to hypoxia (17).

In summary, our data taken together with previous observations, is consistent with the interpretation of cosecretion of the enkephalin peptides with catecholamines during periods of physiologic stress in the intact animal. These data also suggest incomplete processing of the large mol wt peptides occurs before secretion. Where further processing of these large mol wt en- 
kephalins occurs and where these circulating peptides exert their physiologic effect is unclear. Further work to determine the source of the circulating peptides, site of action, and whether the increased plasma levels of the enkephalin peptides represent increased secretion or simply altered clearance or metabolism remains to be examined.

\section{REFERENCES}

1. Lagamma EF, Itskovitz J, Rudolph AM 1983 Maturation of circulatory responses to methionine-enkephalin. Pediatr Res 17:162-167

2. Chernick V 1981 Endorphins and ventilatory control. N Engl J Med 304:12271228

3. McQueen DS 1983 Opioid peptide interactions with respiratory and circulatory systems. Br Med Bull 39:71-75

4. Holaday JW 1983 Cardiovascular effects of endogenous opiate systems. Annu Rev Pharmacol Toxicol 23:541-594

5. Konishi S, Tsunoo A, Otsuka M 1981 Enkephalins presynaptically inhibit cholinergic transmission in sympathetic ganglia. Nature 282:515-516

6. Konishi S, Tsunoo A, Otsuka M 1981 Enkephalin as a transmitter for presynaptic inhibition in sympathetic ganglia. Nature 294:80-82

7. Kumakura K, Karoum F, Guidotti A, Costa E 1980 Modulation of nicotinic receptors by opiate receptor agonists in cultured adrenal chromaffin cells. Nature 283:489-492

8. North RA, Egan TM 1983 Actions and distributions of opioid peptides in peripheral tissues. Br Med Bull 39:71-75

9. Viveros OH, Diliberto Jr EJ, Hazum E, Cheng K 1979 Opiate-like materials in the adrenal medulla: evidence for storage and secretion with catecholamines. Mol Pharmacol 16:1101-1108

10. Winkler H, Apps DK, Riscer-Colbrie R 1986 The molecular function of adrenal chromaffin granules: established facts and unresolved topics. Neuroscience 18:261-290

11. Chaminade M, Foutz AS, Rossier J 1984 Co-release of enkephalins and precursors with catecholamines from the perfused cat adrenal gland in situ. J Physiol 353:157-169

12. Comline RS, Silver M 1961 The release of adrenaline and noradrenaline from the adrenal glands of the foetal sheep. J Physiol 156:424-444

13. Seidler FJ, Slotkin TA 1985 Adrenomedullary function in the neonatal rat: responses to acute hypoxia. J Physiol 358:1-16

14. Vogel Z, Alstein M 1977 The adsorption of enkephalin to porous polystyrene beads: A simple assay for enkephalin hydrolysis. FEBS Lett 80:332-335
15. Peuler JD, Johnson GA 1977 Simultaneous single isotope radioenzymatic assay of plasma norepinephrine, epinephrine and dopamine. Life Sci 21:626636

16. Cohen V 1981 Endorphins and ventilatory control. N Engl J Med 304:12271228

17. Martinez A, Padbury J, Shames L, Evans C, Humme J 1988 Naloxone potentiates epinephrine release during hypoxia in fetal sheep: dose response and cardiovascular effects. Pediatr Res 23:343-347

18. Farrell LD, Harrison TS, Demers LM 1983 Immunoreactive met-enkephalin in the canine adrenal: response to acute hypovolemic stress. Proc Soc Exp Biol Med 173:515-518

19. Gaumann DLM, Yaksh TL 1988 Effects of hemorrhage and opiate antagonists on adrenal release of neuropeptides in cats. Peptides 9:393-405

20. Medbak S, Mason DFJ, Rees LH 1987 Plasma met-enkephalin and catecholamines responses to insulin-induced hypoglycemia in greyhounds. J Endocrinol 114:81-87

21. Edwards AV, Hansell D, Jones CT 1986 Effects of synthetic adrenocorticotrophin on adrenal medullary responses to splanchnic nerve stimulation in conscious calves. J Physiol 379:1-16

22. Singer EA, Mitra SP, Carraway RE 1986 Plasma protein(s) yields met-enkephalin-related peptides in near-micromolar concentrations when treated with pepsin. Endocrinology 119:1527-1533

23. Shen FS, Lindberg I 1987 Plasma opioid peptides: characterization of metenkephalin-immunoreactive peptides generated by peptic digestion. Soc Neurosci 13:1278

24. Holaday JW, A'Amato RJ, Ruvio BA, Feuerstein G, Faden Al 1983 Adrenalectomy blocks pressor responses to naloxone in endotoxic shock: Evidence for sympathomedullary involvement. Circ Shock 11:201-210

25. Holaday JW, Faden AI 1978 Naloxone reversal of endotoxin hypotension suggests role of endorphins in shock. Nature 275:450-451

26. Hughes GS Jr 1984 Naloxone and methylprednisolone sodium succinate enhance sympathomedullary discharge in patients with septic shock. Life Sci 35:2319-2326

27. McIntosh TK, Palter M, Grasberger R, Vezina R, Yeston NS, Egdahl RH 1985 Effect of an opiate antagonist (Naloxone) and an agonist/antagonist (Nalbuphine) in primate hemorrhagic shock: relationship to catecholamine release. Circ Shock 17:313-325

28. Schadt JC, Gaddis RR 1985 Endogenous opiate peptides may limit norepinephrine release during hemorrhage. J Pharmacol Exp Ther 232:656-660

29. Faden AI Holaday JW 1978 Opiate antagonists: a role in the treatment of hypovolemic shock. Science 205:317-318

30. Furman Wl, Menke JA, Barson WJ, Miller RR 1984 Continuous naloxone infusion in two neonates with septic shock. J Pediatr 105:649-651 